\section{The perception of illusory contours in the hypercyclopean domain}

\section{PARDO MUSTILLO and ROBERT FOX \\ Vanderbilt University, Nashville, Tennessee}

There is renewed interest in the study of illusory contours, so much so that an international conference devoted exclusively to this phenomenon was recently held (see Petry \& Meyer, 1986). Much of the mystery surrounding illusory contours concerns how they can be perceived in the absence of physical discontinuities in luminance. Indeed, a major theme of research on illusory contours is the specification of the relevant stimulus parameters in the luminance domain required for their formation. A good example of this approach is the recent work of Prazdny $(1985,1986)$, who has argued that (1) luminance differences must be present in order for illusory contours to be perceived, and (2) differences in temporal correlation between the background and the inducing elements elicit the perception of illusory contours in random-dot cinematograms.

In this paper, we report several observations relevant to this issue that cast doubt on the assertions that luminance-domain information or spatiotemporal differences are essential variables for the induction of illusory contours. In short, we have found that observers can readily perceive illusory contours induced solely by global stereoscopic forms under stimulus conditions in which neither monocular luminance differences nor motion discontinuities are present.

To produce these forms, we used a hard-wired electronic system that generates, on modified color television receivers, dynamic matrices of randomly ordered red and green dots. All elements in the matrices are replaced randomly at a field rate of $60 \mathrm{~Hz}$, resulting in apparent motion of the elements that resembles Brownian motion. Such motion, however, does not impair the perception of global stereoscopic forms, which can be presented for controlled durations and moved about quickly to virtually any position in stereoscopic space. A unique feature of the system is an image digitizer that converts any twodimensional achromatic shape into a global stereoscopic form of equivalent configuration. (For a more complete description of this system, see Lehmkuhle \& Fox, 1980, and Shetty, Brodersen, \& Fox, 1979.)

For our purposes, we presented to the digitizer inducing elements (Pac Man) arranged to produce simple Kanizsa-type illusory squares, rectangles, and triangles

\footnotetext{
Support for this investigation was provided by Grant EY00590-22 from the National Institutes of Health. We would like to thank Susan Petry for her comments on a previous version of this manuscript. Requests for reprints should be addressed to Robert Fox, Department of Psychology, Vanderbilt University, Nashville, TN 37240.
}

of varying sizes (i.e., $5.5^{\circ}, 6.8^{\circ}, 8.2^{\circ}$ ). The stereoscopic displays were completely devoid of any monocular or brightness cues, and no motion or texture discontinuities were present at any time between the illusory figures and the inducing elements; the inducing elements were specified entirely by horizontal binocular disparity.

We had 15 observers, 8 of whom were inexperienced with random element stereograms, view the resulting stereoscopic displays for an unlimited duration from a distance of $250 \mathrm{~cm}$. Each was tested individually. To comply with the requirements of the anaglyphic method of stereoscopic presentation, each observer wore spectacle frames to which appropriately matched red and green filters were affixed. When the inducing elements contained uncrossed disparity and appeared behind the plane of the display, 12 of the 15 observers reported seeing distinct illusory contours and surfaces, with the illusory surfaces bounded by the contours appearing clearly segmented above or in front of the apparent depth plane of the inducing elements $(p=.0278$, binomial test, two-tailed). This effect was present for all configurations and sizes of the Kanizsa figures.

The magnitude of retinal disparity, which ranged from $6.9^{\prime}$ to $32^{\prime}$ of arc, did not appear to be a critical variable, although observers did express a preference for a disparity of about $15^{\prime}$ of arc. The direction of disparity, however, was a critical variable. When the inducing elements were presented with crossed disparity and thus appeared to lie in depth in front of the display, they clearly stood out as independent entities, but they no longer appeared united by an illusory contour and surface. In this condition, only 2 of the 15 observers reported seeing faint illusory edges, but none reported seeing any segmentation of the illusory surface from the random element background. The importance of uncrossed disparity for the perception of illusory figures is probably related to the fact that it complies with the conditions intrinsic to the luminance domain whereby the illusory contour and surface appear as figure against the ground provided by the inducing elements.

In view of our success in inducing illusory contours solely through the use of stereoscopic stimuli, Frazdny's (1985) recent failure to obtain such induction under somewhat similar conditions is of particular interest. Although it is difficult to specify the exact reasons for the difference in results between our study and his, one possibility might be related to the size of the inducing elements. In Prazdny's study, the gap in the inducing elements subtended $27^{\prime}$ of arc at its widest extent. This corresponds to a spatial frequency of about 1.1 cycles per degree (cpd). In the stereoscopic analogue of the contrast sensitivity function, sensitivity to disparity begins falling off at frequencies greater than about $1 \mathrm{cpd}$ (Rogers \& Graham, 1982) and reaches a cutoff at about 3-4 cpd (e.g., Tyler, $1973,1974)$. This suggests that the frequencies 
represented by the gaps in the inducing elements in Prazdny's displays were so high that they could not be properly resolved spatially. On that point, we found it impossible to induce illusory contours with elements of the size used by Prazdny. On the other hand, we obtained successful induction with larger inducing elements where the gap at its widest extent was 55' of arc, which corresponds to a spatial frequency of about $0.55 \mathrm{cpd}$. It has been noted that observers are highly sensitive to this frequency in dynamic random-dot stereogratings (e.g., Rogers \& Graham, 1982; Schumer \& Ganz, 1979). One reason for placing this emphasis on spatial frequency is that we think we have found a robust phenomenon that can readily be replicated by others so long as two critical requirements are fulfilled: First, the inducing elements should have uncrossed disparity, and second, they should contain sufficiently large gaps.

Although results ostensibly similar to ours have been reported previously under dichoptic viewing conditions with a variety of stimulus patterns (e.g., Blomfield, 1973; Gregory \& Harris, 1974; Harris \& Gregory, 1973; Lawson, Cowan, Gibbs, \& Whitmore, 1974; Ramachandran, 1986; Ramachandran \& Cavanagh, 1985; Whitmore, Lawson, \& Kozora, 1976), all of these studies used stimulus displays that contained monocular cues and a luminance mismatch or difference between the inducing elements and the illusory figure. In contrast, our results indicate that neither differences in luminance nor differences in temporal correlation (i.e., motion discontinuities) are necessary for the production of illusory contours. Rather, the critical variables appear to be the size and the disparity direction of the inducing elements. The irrelevance of luminance differences implies that the formation of illusory contours in the luminance domain may constitute a special rather than the general case.

Finally, our successful induction of illusory contours through the use of global stereoscopic stimuli means that they can be added to the growing list of phenomena that can be encompassed by the concept of hypercyclopean perception. That term refers to the perceptual phenomena from the luminance domain that can be replicated or reproduced in the stereoscopic domain by means of random element stereograms or cyclopean stimulation (see Julesz \& Schumer, 1981, and Tyler, 1983, for reviews of hypercyclopean research). It is generally conceded that the existence of hypercyclopean phenomena renders in- complete attendant explanations or models based exclusively on data from the luminance domain, and this conclusion, therefore, must apply with equal force to illusory contours.

\section{REFERENCES}

BlomfIELD, S. (1973). Implicit features and stereoscopy. Nature, 245, 256.

Gregory, R. L., \& HaRRIS, J. P. (1974). Illusory contours and stereo depth. Perception \& Psychophysics, 15, 411-416.

Harris, J. P., \& GrEgory, R. L. (1973). Fusion and rivalry of illusory contours. Perception, 2, 235-247.

Julesz, B., \& SChumer, R. A. (1981). Early visual perception. An nual Review of Psychology, 32, 575-627.

LAWSON, R. B., CowaN, E., GrBBS, T. D., \& WhITMORE, C. G. (1974), Stereoscopic enhancement and erasure of subjective contours. Journal of Experimental Psychology, 103, 1142-1146.

LeHmkUhle, S., \& Fox, R. (1980). Effect of depth separation on metacontrast masking. Journal of Experimental Psychology: Human Perception \& Performance, 6, 605-621.

Petry, S., MeYer, G. E. (1986). Adelphi International Conference on Illusory Contours: A report on the conference. Perception \& Psychophysics, 39, 210-221.

PrazDNY, K. (1985). On the nature of inducing forms generating perceptions of illusory contours. Perception \& Psychophysics, 37, 237-242.

Prazdny, K. (1986), Illusory contours from inducers defined solely by spatiotemporal correlation. Perception \& Psychophysics, 39, 175-178.

RamaChandRan, V. S. (1986). Capture of stereopsis and apparent motion by illusory contours. Perception \& Psychophysics, 39, 361-373.

Ramachandran, V. S., \& Cavanagh, P. (1985). Subjective contours capture stereopsis. Nature, 317, 527-530.

ROGERS, B., \& GRAHAM, M. (1982). Similarities between motion parallax and stereopsis in human depth perception. Vision Research, 22, 261-270.

SCHUMER, R., \& GANZ, L. (1979). Independent stereoscopic channels for different extents of spatial pooling. Vision Research, 19, 1303-1314.

ShetTy, S. S., Brodersen, A. J., Fox, R. (1979). System for generating dynamic random-element stereograms. Behavior Research Methods \& Instrumentation, 11, 485-490.

TYLER, C. W. (1973). Stereoscopic vision: Cortical limitations and a disparity scaling effect. Science, 181, 276-278.

TYLER, C. W. (1974). Depth perception in disparity gratings. Nature, 251, 140-142.

TYLER, C. W. (1983). Sensory processing of binocular disparity. In C. M. Schor \& K. J. Cuiffreda (Eds.), Vergence eye movements: Basic and clinical aspects (pp. 199-295). Boston: Butterworths.

WhitMore, C. L. G., LAwSON, R. B., \& Kozora, C. E. (1976). Subjective contours in stereoscopic space. Perception \& Psychophysics, 19, 211-213.

(Manuscript received September 8, 1986; accepted for publication September 18, 1986.) 